DOI 10.5216/ia.v45i3.64915

\title{
REMINISCÊNCIAS DO PATRIMONIALISMO NO PLANO NACIONAL DE EDUCAÇÃO (2014-2024)
}

\author{
Heitor Lopes Negreiros \\ FRANCEILA AUER \\ WAGNER DOS SANTOS \\ ELIZA BARTOLOZZI FERREIRA \\ Universidade Federal do Espírito Santo (Ufes), Vitória, Espírito Santo, Brasil
}

\begin{abstract}
Resumo: Este artigo tem por objetivo analisar o modo como as metas e as estratégias do Plano Nacional de Educação (2014-2024) evidenciam, na relação públicoprivado, as transformações e as permanências do patrimonialismo brasileiro. Caracteriza-se como uma pesquisa documental e tem como fonte o Plano Nacional de Educação (2014-2024). Dentre o aporte teórico, mobiliza os conceitos de patrimonialismo e de relação público-privado. Utiliza como instrumento, para auxílio da produção dos dados, o software IRAMUTEQ. Os resultados sinalizam para uma permanência do patrimonialismo brasileiro, porém com modificações na relação público-privado em decorrência do fortalecimento das entidades do terceiro setor.
\end{abstract}

Palavras-chave: Educação. Plano Nacional de Educação. Patrimonialismo. Relações Público-privadas.

\section{INTRODUÇÃO}

Este artigo tem por objetivo analisar o modo como as metas e as estratégias do Plano Nacional de Educação (PNE, 2014-2024) evidenciam, na relação público-privado, as transformações e as permanências da dominação da elite brasileira por meio das práticas patrimonialistas. Para tanto, estabelecemos como fonte o documento do PNE (2014-2024) e, para compor nossas categorias de análise, apropriamo-nos do pensamento de Sérgio Buarque de Holanda $(1971,1995)$ e de Raymundo Faoro (1993, 2017). As marcas do patrimonialismo na formação do Brasil são objetos de estudo dos intelectuais brasileiros que buscaram compreender as raízes do desenvolvimento do país, desde a Colônia até a República.

Nesse caso, é inadequado analisarmos tais relações como se fossem harmoniosas. Pelo contrário, partimos do pressuposto de que as políticas educacionais acontecem em um país marcado pelo patrimonialismo, isto é, com dificuldades de distinguir o público do privado. Para Mendonça (2001, p. 95), na constituição do país, "[...] mais que um Estado patrimonial puro, consideram-se os traços, as atitudes e os valores da dominação tradicional que subsistiram no Estado brasileiro, criando um modelo híbrido de burocracia patrimonial". 
Não obstante o fato de o campo da política educacional reconhecer que a produção das políticas educacionais faz parte de uma ação pública que envolve múltiplos atores (públicos e privados), o Estado continua um ator importante e mantém práticas historicamente constituídas em uma sociedade conservadora e que preserva as desigualdades sociais e econômicas como uma das suas características principais. $\mathrm{O}$ patrimonialismo é um desses "ismos" que permanecem, mesmo que eles possam apresentar feições variadas de acordo com o contexto.

A relação "promíscua"1 entre o público e o privado na educação pode ser compreendida como um desdobramento do patrimonialismo que ainda se faz presente na atualidade. Porém, o que identificamos, nos últimos anos, foi uma transformação na maneira pela qual o patrimonialismo brasileiro vem se constituindo no âmbito educacional após as reformas neoliberais, caracterizadas, sobretudo, pela descentralização da gestão da educação nos moldes da Nova Gestão Pública. O movimento global do capital financeiro impõe novas e diversas formas de privatização da educação brasileira, as quais convivem com práticas internas patrimonialistas submetidas à globalização da educação. Isso significa a manutenção da política de modernização conservadora do país que subordina os interesses nacionais de uma pequena elite (patrimonialista) à agenda global de expansão da educação como mercadoria.

Este artigo está organizado em duas sessões: a primeira apresenta questões teóricas sobre o patrimonialismo no Brasil, a metodologia do estudo e evidencia as possibilidades do software IRAMUTEQ para a análise do PNE (2014-2024), a segunda contempla os dados encontrados na pesquisa e o seu diálogo com a literatura base do estudo.

\section{TEORIA E MÉTODO}

Ao abordar a constituição do Estado brasileiro no início do século XX, Holanda (1995) o considera atrelado a um paradigma doméstico, no qual a gestão pública foi invadida por interesses privados que não tinham como horizonte o bem comum. Para Holanda (1995, p. 141), "[...] o Estado não é uma ampliação do círculo familiar e, ainda menos, uma interação de certos agrupamentos, de certas vontades particularistas, de que a família é o melhor exemplo".

Nesse contexto, Holanda (1995) discorre sobre a figura do "homem cordial". Grosso modo, trata-se daquele que não consegue discernir o privado do público, o que faz com que ele utilize comportamentos e valores familiares na esfera pública. De certa forma, o "homem cordial" reduz as relações impessoais a um padrão de afetividade. Mas essa personalidade amigável não pressupõe bondade e civilidade. Segundo o autor, as características do "homem cordial" são "[...] antes de tudo expressões legítimas de um fundo emotivo extremamente rico e transbordante" (HOLANDA, 1995, p. 147), as quais mascaram seu modo equivocado de viver em sociedade.

Holanda (1971) aponta que um dos aspectos da cultura política brasileira é o favorecimento dos laços de amizade e a proximidade pessoal na hora de realizar escolhas referentes àquilo que é público. Para o autor (1971, p. 106), “[...] as relações que 
NEGREIROS, H. L.; AUER, F.; SANTOS, W. do; FERREIRA, E. B.

se criam na vida doméstica sempre forneceram o modelo obrigatório de qualquer composição social entre nós". O autor acreditava que a impessoalidade, fruto do liberalismo democrático, nunca teria se naturalizado entre nós, pois não compunha o rol de características formadoras da cultura política brasileira.

Desse modo, a ausência da impessoalidade sustenta a supressão do público pelo privado, pois, se os interesses privados - portanto pessoais - são estabelecidos como prioridade, a naturalidade é oposta à proposta do liberalismo democrático, em que valores como pessoalidade, amizade, compadrio e patronagem ocupam o espaço.

Nesse sentido, Faoro (2017) relaciona as características das mazelas brasileiras com a estrutura patrimonialista estamental herdada do Estado português. Para Faoro (1993, p. 25), “[...] a presença do patrimonialismo se prova pela história, uma história que começa em Portugal e ainda está em curso. Ele vive, atua, se dissimula e emerge debaixo de uma máscara capitalista".

Este artigo se caracteriza como uma pesquisa qualitativa do tipo documental e tem como fonte o PNE (2014-2024). Optamos pelo mais recente PNE como fonte primária de análise por se tratar de um documento que traça o horizonte educacional em longo prazo. Dessa forma, compreendemos como as reminiscências patrimonialistas são estabelecidas na atualidade e como se comportam no processo de transição de governos. Todavia, a partir do PNE, houve necessidade de analisar outras fontes, como relatórios, pareceres e diretrizes do próprio governo brasileiro e, também, de organismos transnacionais.

Para análise da fonte, utilizamos, como instrumento de auxílio e organização, o software IRAMUTEQ. Selecionamos o texto do PNE (2014-2024) em sua integralidade, transferindo-o a blocos de notas (arquivo.txt). Em seguida, ele foi importado para o software, onde geramos a "árvore de similitude" (Figura 1) e a "Classificação Hierárquica Descendente" (CHD) (Figura 2). A utilização do software não dispensou a leitura e a análise criteriosa do documento, que foi utilizado para o refinamento das análises.

\section{O PLANO NACIONAL DE EDUCAÇÃO (2014-2024): ALGUMAS ANÁLISES}

O PNE (2014-2024) foi sancionado pelo Congresso Nacional e aprovado em junho de 2014 com o objetivo de melhorar a qualidade da educação do país. Estabelece metas, diretrizes e estratégias previstas para serem cumpridas no decorrer dos dez anos de sua vigência. Também se prevê o acompanhamento contínuo do PNE a fim de haver a verificação/avaliação do que ele se propõe cumprir. Além disso, é composto por 20 metas que contemplam todas as etapas e as modalidades da educação brasileira e abrange questões sobre financiamento e gestão educacional.

No primeiro parágrafo do PNE, O Ministério da Educação vincula a complexidade do modelo federativo brasileiro com a visão patrimonialista "[...] que ainda resiste em muitos setores da gestão pública" (BRASIL, 2014, p. 5). Essa característica da organização da política nacional foi utilizada como justificativa para a construção de formas orgânicas de colaboração entre os sistemas de ensino, de modo que esse é o cerne do PNE. Assim, “[...] se por um lado o Estado se coloca como provedor da política educacional, por outro, ao injetar recursos públicos no setor privado educacional, administra o setor com escassez monetária, o que retrai o direito à educação pública" (FERNANDES; BRITO; PERONI, 2012, p. 567). 
Para compreendermos essas relações com a esfera privada, elaboramos a Figura 1, no IRAMUTEQ, no algoritmo "árvore de similitude", que, além de nos apresentar as conexões de relevância do âmbito privado com a educação, agrupou as palavras de maior conexão em clusters (por assuntos).

Figura 1 - Árvore de similitude "Privatização" do PNE (2014-2024)

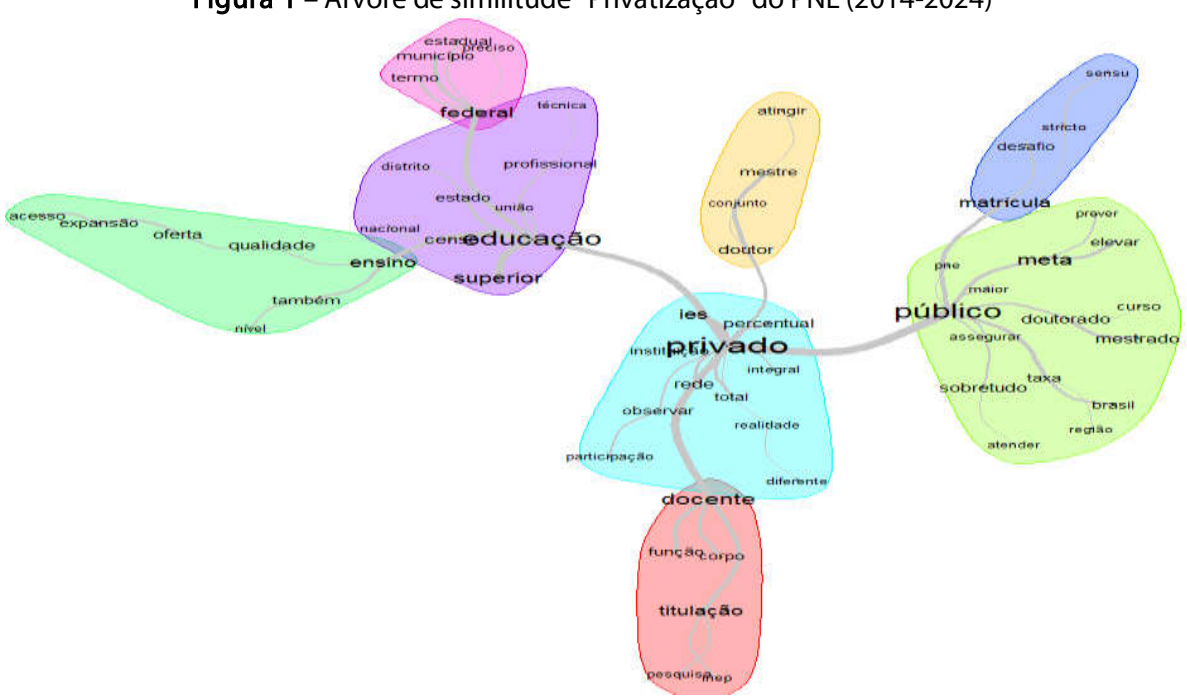

Fonte: Elaborada pelos autores.

Selecionamos os parágrafos das palavras que continham o prefixo "priv" no PNE e, consequentemente, a palavra que aparece no centro e em maior relevância é "privado", capitaneando o cluster azul claro; de "privado", saem cinco arestas, as linhas que o ligam a outras palavras. Quanto maior a espessura da aresta, maior a relação das palavras por ela conectadas. A relação público-privado é o que aparece em destaque e com maior conexão na Figura 1.

De maneira geral, quando analisamos as fontes na sua relação com o contexto histórico, identificamos que o PNE e o encaminhamento de outras políticas educacionais vindas em seu contexto - a exemplo da Base Nacional Comum Curricular (BNCC) -, ocorreram no governo Dilma Roussef, mas as bases constituidoras desse processo foram anteriormente estabelecidas com Fernando Henrique Cardoso (FHC).

O projeto reformista de FHC teve suas bases assentadas nas recomendações de organismos, como o Banco Mundial (BM) e Fundo Monetário Internacional (FMI), nas quais ao Estado caberia privatizar o que não fosse serviço social essencial. Ou seja, não houve um rompimento da lógica das políticas educacionais, em que pese o fato de o processo de elaboração do PNE ter uma característica inovadora e participativa, conforme a realização das conferências nacionais, estaduais e municipais. Assim, as apropriações feitas, desde o processo de redemocratização do país, não estavam desvinculadas da intervenção das instituições multilaterais. 
NEGREIROS, H. L.; AUER, F.; SANTOS, W. do; FERREIRA, E. B.

Faoro (2017) apresentou as diversas nuanças do processo histórico que amalgamou o público e o privado no Estado brasileiro que persistem em diferentes versões nos dias de hoje. O capitalismo politicamente orientado caracteriza-se, no Brasil, por um controle político da economia, fazendo com que o público e o privado se confundam, com desprezo da lisura e da impessoalidade.

Quando o PNE faz menção ao ensino profissional, é destacada a relação público-privado para justificar o crescimento do número de matrículas, identificando que "[...] essa modalidade de educação está sendo ofertada em estabelecimentos públicos e privados, que se caracterizam como escolas técnicas, agrotécnicas, centros de formação profissional, associações, escolas, entre outros" (BRASIL, 2014, p. 39).

O documento do PNE também demarca a vinculação de público e privado em relação ao ensino superior ao citar a Meta 13, que dispõe sobre a necessidade de aumentar o número de mestres e doutores no país, porém considera que isso é uma responsabilidade tanto das instituições públicas como das privadas: "[...] a Meta 13 do PNE pretende elevar a proporção de mestres e doutores do corpo docente em efetivo exercício no conjunto do sistema de educação superior (instituições públicas e privadas)" (BRASIL, 2014, p. 43).

Os elaboradores do PNE partem do pressuposto de que as instituições de ensino superior (IES) públicas já cumpriram o que determina a Meta 13, contudo o mesmo processo não acontece com as IES privadas. Dessa forma, a referida meta se destina mais ao setor privado do que efetivamente ao setor público, visto que uma das estratégias para o cumprimento da meta é o fortalecimento do Sistema de Avaliação da Educação Superior.

Esse processo justifica a criação do cluster amarelo (Figura 1), capitaneado pela palavra "doutor", seguida de "mestre", "conjunto" e "atingir". Esse cluster está diretamente ligado a "privado", pois a ideia é que as IES públicas já atingiram as metas previstas nesse quesito. O cluster vermelho também está relacionado com a Meta 13 e com o aumento do número de mestres e doutores no corpo docente das IES privadas. A palavra INEP - sigla do Instituto Nacional de Estudos e Pesquisas Educacionais Anísio Teixeira - aparece no final do cluster vermelho, associada à estratégia para o alcance da meta de fortalecimento da avaliação, política de responsabilidade direta dessa instituição.

A segunda aresta mais espessa da Figura 1 liga o cluster verde ("privado") ao cluster roxo, capitaneado pela palavra "educação". O cluster rosa, liderado pela palavra "federal", e o cluster verde florescente fazem intersecção com o cluster roxo, capitaneado pela palavra "educação". Consideramos que a conexão de "privado" a esses clusters se vincula pela generalidade dos objetivos em universalizar o ensino obrigatório, pela garantia de um ensino público de qualidade e pela regulação do ensino privado.

Podemos observar o protagonismo que a esfera privada ocupa em alguns pontos do PNE no que diz respeito às menções ao longo de seu texto direcionadas ao destaque de que, para haver a universalização do ensino, é preciso que a parceria entre o público e o privado seja precípua. A respeito disso, há metas vinculadas muito mais ao setor privado do que ao setor público, a exemplo da Meta 1, como facilitadora desse processo, uma vez que as muitas prefeituras preferem "comprar" vagas em instituições de educação infantil da rede privada ao invés de construir creches e pré-escolas públicas.

Inter-Ação, Goiânia, v.46, n.1, p. 149-165, jan./mar. 2021. Disponível em: <http://dx.doi.org/10.5216/ia.v45i3.64915>. 
Pinto (2016) apontou o crescimento gradativo com tendência de aumento nos próximos anos do repasse de recursos públicos às instituições privadas de educação infantil. Nessa direção também está a Meta 14, que determina o aumento do número de doutores para a esfera privada (o que demandará aumento do repasse e de fornecimento de bolsas por parte do setor público).

A partir da Figura 2, produzida utilizando o algoritmo CHD, realizou-se um movimento de análise que consistiu em produzir categorias a posteriori, tomando como referência as classes por ela geradas (cores das palavras). Nesse caso, definimos, a partir dessas classes, as seguintes categorias: classe vermelha, "Educação Básica"; verde, "Pacto Federativo"; azul, "Profissional"; roxa, "Ensino Superior".

As palavras que aparecem em maior tamanho representam sua abrangência e relevância dentro da classe. As palavras vão diminuindo à medida que assumem menor destaque na classe. Analisada por uma perspectiva tridimensional, a Figura 2 sinaliza que as palavras em maior tamanho são aquelas que se destacam no PNE e, consequentemente, dentro das classes, compondo um rol de palavras-chave. Nesse caso, de acordo com a Figura 2, a classe vermelha ("Educação Básica") concentra, no seu rol de palavras, aquelas que assumem o cerne do documento. Liderada pela palavra "escolar" e pela palavra "pedagógico", essa categoria demonstra que o maior número de metas do PNE está voltado para a educação básica e para os aspectos do ensino e do pedagógico propriamente dito.

Figura 2 - Categorias das classes do PNE (2014-2024)

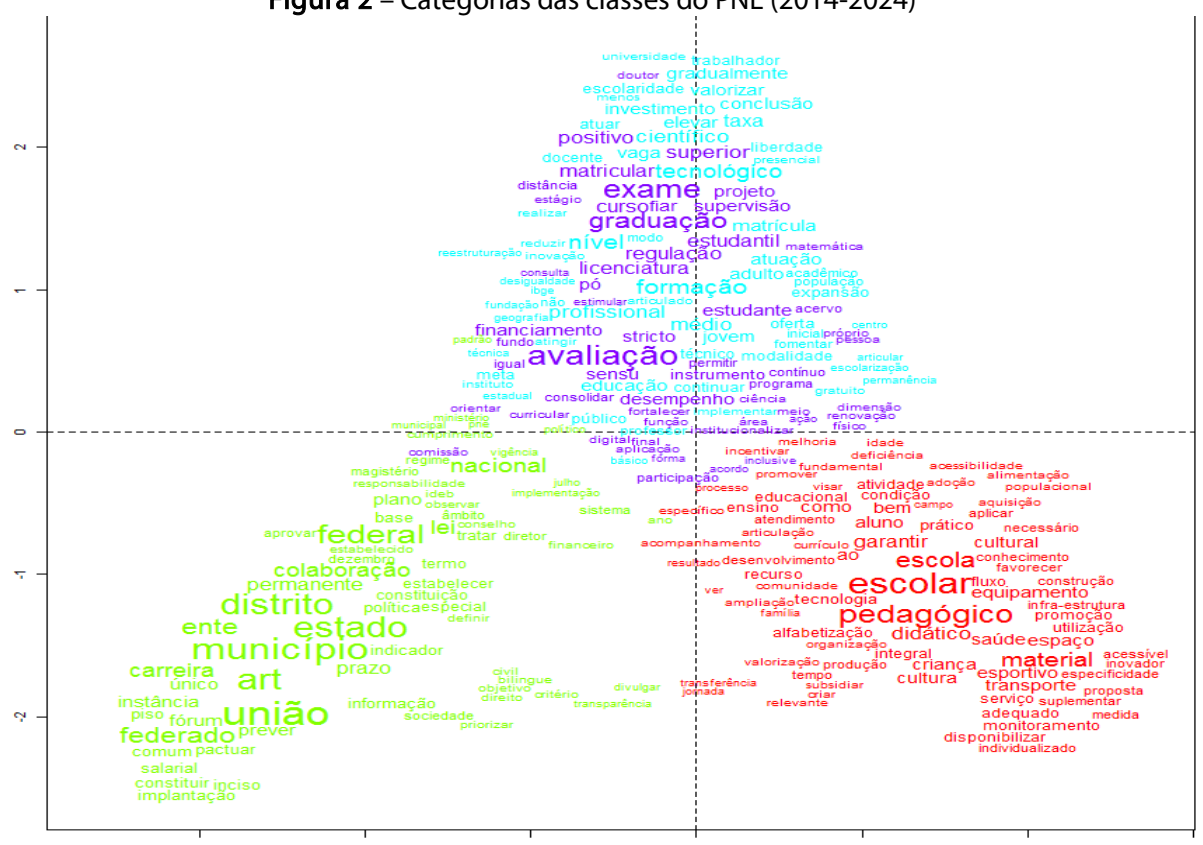

Fonte: Elaborada pelos autores. 
NEGREIROS, H. L.; AUER, F.; SANTOS, W. do; FERREIRA, E. B.

Ao remeter a expressão "oferta gratuita", o PNE normatiza que as instituições privadas recebam investimentos públicos desde que os utilizem nas respectivas áreas de ensino tratadas pelas metas, conforme observado nas Estratégias: 1.7, 3.7, 8.4, 9.1 e 11.6.

Apesar de a Estratégia 11.7 da Meta 11 não ter em seu texto a expressão "oferta gratuita", ela discorre sobre a legitimidade do financiamento estudantil nas instituições privadas de ensino superior. Além disso, compreendemos que as Estratégias 4.17 (promove parcerias com instituições privadas), 12.5 (potencializa o Fundo de Financiamento Estudantil - Fies), 12.19 (atribui celeridade ao reconhecimento de cursos superiores) e 14.3 (expande o Fies) expressam incidências de um Estado patrimonialista, por atribuírem maior robustez à relação público-privado.

A Meta 1 do PNE (2014, p. 2), que trata da educação infantil, traz em sua Estratégia 1.7: "[...] articular a oferta de matrículas gratuitas em creches certificadas como entidades beneficentes de assistência social na área de educação com a expansão da oferta na rede escolar pública". Embora haja uma proposta da expansão da oferta da educação infantil na rede pública, caso seja ineficiente, pessoas jurídicas de direitos privados podem ofertar as matrículas. Ainda que a compra de vagas em instituições privadas seja realizada como uma medida paliativa, compreendemos que essa solução passa a ser legitimada nos termos da lei.

Araújo (2015) discorre sobre o forte subsídio das redes municipais ao setor privado para a oferta das matrículas na educação infantil, o que, para o autor, é uma situação inesperada, visto que, se os índices de acesso à educação infantil aumentassem, esperar-se-ia uma intervenção menor do setor privado. Esse aspecto permite aos municípios - que têm a responsabilidade pela educação infantil - contratar os serviços privados por meio de convênios para suprir a demanda desse segmento. Geralmente essa contratação é vista como gerencialmente mais eficaz pelas prefeituras municipais. A meta em questão está alinhada ao que está previsto na Lei de Diretrizes e Bases (LDB/1996), art. 77, que dispõe sobre a alocação dos recursos públicos.

Assim, o imbricamento do público com o privado permanece forte mesmo em uma legislação que fez parte do rol de reformas administrativas do Estado (desde o governo $\mathrm{FHC}$ ), as quais visavam combater o patrimonialismo, porém não enfrentaram o problema de forma radical. Esse exemplo revela o quanto é forte a cultura patrimonialista no Brasil do final do século XX.

Compreendemos que o caráter patrimonialista do Estado faz emergir ações empreendidas pelo capital. Assim, "[...] para ter acesso e controle sobre o fundo público — via setor educacional - [que] se diversificam e ganham complexidade, torna-se difícil separar os interesses privados por áreas de atuação" (MINTO, 2018, p. 6). Para reverter essa situação, concordamos com Holanda (1995, p. 145), ao ressaltar que deve haver "[...] distinção fundamental entre os domínios do privado e do público". Além disso, o planejamento da educação brasileira requer uma ação assentada em um projeto nacional de garantia do direito à educação pública, gratuita e laica para toda a população, sem distinção de classe, gênero ou raça.

Ainda destacamos a Estratégia 2.2, da Meta 2, que se refere ao ensino fundamental e se propõe:

Pactuar entre União, Estados, Distrito Federal e Municípios, no âmbito da instância permanente [...] a implantação dos direitos e objetivos de aprendizagem e desenvolvimento que configurarão a 
base nacional comum curricular do ensino fundamental. (BRASIL, 2014, p. 5).

A derivação dessa meta, no contexto atual de perdas dos direitos, abriu uma janela de oportunidades para o setor privado, mobilizado pelo grupo de entusiastas pela base comum no sentido de "privatizar" o currículo, a exemplo do Movimento pela Base Nacional, que é constituído por grupos privados, criado em 2013, e atua na elaboração de políticas educacionais de caráter utilitarista e instrumental, em alinhamento com as diretrizes de organismos multilaterais, como a Unesco e o BM.

No relatório Um ajuste justo - análise da eficiência e equidade do gasto público no Brasil (BANCO MUNDIAL, 2017), o BM propõe à área educacional brasileira um conjunto de reformas para aumentar a eficiência e a eficácia com o objetivo de reduzir o custo fiscal. Dentre essas sugestões, estão a reforma educacional e a formação de professores. A reforma educacional também é uma das saídas apresentadas no relatório Professores excelentes - como melhorar a aprendizagem dos estudantes na América Latina e no Caribe (BRUNS; LUQUE, 2014) para a educação brasileira. O foco seria a reforma do currículo. Para Hypólito (2019), a BNCC foi constituída como um modelo gerencialista apoiada por

[...] grupos e instituições ligadas ao Todos pela Educação e por lobbies de fundações, institutos e entidades, com ou sem fins lucrativos, com interesses muito definidos em torno de um mercado educacional bilionário que envolve venda de materiais pedagógicos, consultorias privadas e prestação de serviços, a fim de substituir o que hoje é realizado pelas escolas e pelo sistema público de educação. (HYPÓLITO, 2019, p. 194).

Nesse sentido, as características patrimonialistas que constituem a cultura política brasileira não estão desconectadas das políticas externamente orientadas, pois, quando os organismos internacionais interferem na educação, essa interferência é desenvolvida de forma mesclada com a cultura interna do país. Esse movimento é característico de nossa história desde o acordo MEC-Usaid (durante o regime militar), até as influências de organismos, como BM, FMI, Banco Interamericano de Desenvolvimento (BID) e Organização para a Cooperação e Desenvolvimento (OCDE), nas reformas educacionais de FHC (1995-2002), como também em reformas mais recentes.

A Estratégia 3.7, da Meta 3 (BRASIL, 2014), vinculada à categoria “Educação Básica" (palavras em vermelho, da Figura 2), discorre sobre a expansão das matrículas gratuitas de ensino médio integrado à educação profissional, em observância às peculiaridades das populações do campo, indígenas, quilombolas e pessoas com deficiência. Notamos que não há menção ao ensino exclusivamente público. Destacamos que o aumento da oferta e a universalização do atendimento escolar, nos termos em que aparecem no texto da lei, podem abrir espaço para o crescimento privado na educação.

$\mathrm{O}$ atendimento às pessoas com deficiência também é outro ponto de abertura ao setor privado, conforme a Estratégia 4.17: 
NEGREIROS, H. L.; AUER, F.; SANTOS, W. do; FERREIRA, E. B.

\begin{abstract}
Promover parcerias com instituições comunitárias, confessionais ou filantrópicas sem fins lucrativos, conveniadas com o poder público, visando a ampliar as condições de apoio ao atendimento escolar integral das pessoas com deficiência, transtornos globais do desenvolvimento e altas habilidades ou superdotação matriculadas nas redes públicas de ensino. (BRASIL, 2014, p. 7, grifo nosso).
\end{abstract}

Assim, por mais que os discursos de reformas e planos estejam na direção de combate ao patrimonialismo, nos próprios documentos dos governos encontramos a condescendência para que o entrelaçamento entre o público e o privado seja mantido, não mais na apropriação daquilo que é público, mas se tornando cliente, afirmando a evidência de características como compadrio e patronagem. Nesse sentido, a gestão política é dividida com instituições conveniadas de interesses particulares.

Dessa forma, "[...] as funções, os empregos e os benefícios que deles aufere relacionam-se a direitos pessoais do funcionário [patrimonial] e não a interesses objetivos, como sucede no verdadeiro Estado burocrático" (HOLANDA, 1995, p. 146). Consequentemente, pode-se constituir um Estado desprovido de ordenações impessoais e de um caráter burocrático com tendências a dificultar a concretização da educação republicana.

Outro aspecto no qual encontramos a ascensão do privado é na oferta de formações continuadas. Teixeira (2017) compreende que o modus operandi da gestão educacional é influenciado pela relação público-privado, principalmente na busca por melhores resultados e em melhores posicionamentos nos ranqueamentos. Nesse processo, observamos o crescimento da contratação de pacotes para a formação continuada, entretanto isso nem sempre se dá pela contratação direta pelo Poder Público ao setor privado. $O$ autor destaca um novo mercado introduzido pelas fundações que realizam uma espécie de triangulação, à medida que a administração dessas entidades é composta e conduzida por grandes conglomerados educacionais.

Considerando que a Estratégia 8.4 visa a "[...] expandir a oferta gratuita de educação profissional técnica por parte das entidades privadas de serviço social" (BRASIL, 2014, p. 14), observamos que o Programa Nacional de Acesso ao Ensino Técnico e Emprego (Pronatec) é um mecanismo utilizado para ampliar a oferta de cursos profissionais e técnicos. No entanto, essa oferta, destinada a estudantes do ensino médio, da educação de jovens e adultos, a trabalhadores e beneficiários de programas de transferência de renda, pode acontecer por meio de cursos a distância ou em cursos presenciais de instituições públicas ou privadas.

Baseando-se nos dados do Instituto de Pesquisa Econômica Aplicada (2015), Porchmann e Ferreira (2016) destacam que o Pronatec foi criado em 2011 com

[...] estreita parceria com instituições privadas. Foi nesse programa que houve maior investimento financeiro do governo brasileiro, o que fez ter um crescimento de $5,8 \%$ no total de matrículas na educação profissional no biênio 2012-2013, alcançando o patamar de 1,4 milhão de matrículas nas modalidades subsequente, concomitante e integrada ao ensino médio. Nesse período foi observado também um encolhimento da oferta pela rede pública. (PORCHAMANN; FERREIRA, 2016, p. 1248). 
Tendo em vista que a Meta 11, categoria "Profissional", propõe triplicar as matrículas na educação profissional técnica de nível médio de modo a assegurar pelo menos $50 \%$ da expansão no segmento público, a Estratégia 11.6 visa a "[...] ampliar a oferta de matrículas gratuitas de educação profissional técnica de nível médio pelas entidades privadas de formação profissional vinculadas ao sistema sindical e entidades sem fins lucrativos" (BRASIL, 2014, p. 16).

Já a Estratégia 11.7 pretende "[...] expandir a oferta de financiamento estudantil à educação profissional técnica de nível médio oferecida em instituições privadas de educação superior" (BRASIL, 2014, p. 17). Desse modo, observamos que o segmento privado vem interferindo no segmento público, presente em todas as categorias retratadas na Figura 2, por aqueles que defendem a privatização dos serviços públicos identificados no PNE.

A Meta 9 do PNE, que trata da educação de jovens e adultos, tem na Estratégia 9.1 o objetivo de garantir a oferta de suas matrículas gratuitas. Verbos como "garantir", "promover" e "assegurar" se encontram em todo o texto, mas aparecem com destaque na categoria "Educação Básica", como pode ser visto na Figura 2. Entretanto, essa garantia é ampla, podendo ser ofertada ("oferta" aparece na categoria "Profissional") tanto pelo público quanto pelo privado.

A categoria "Ensino Superior" é capitaneada pelas palavras "avaliação" e "exame". Ambas traduzem o processo avaliativo pelo qual os jovens brasileiros devem passar para ingressar no ensino superior. A categoria "Profissional", liderada pelas palavras "nível" e "formação", deve ser analisada juntamente com a categoria "Ensino Superior", por entendermos que o imbricamento das duas é perene, de acordo com a Figura 2.

No que diz respeito aos financiamentos no ensino superior, o Governo Federal criou programas de financiamento público e privado, por exemplo, o Fies e o Programa Universidade para Todos (ProUni). Embora tais programas proporcionem, no Brasil, o acesso de muitas pessoas ao ensino superior, entendemos que os recursos públicos, que poderiam ser utilizados em universidades estaduais e federais, são distribuídos para favorecer o setor privado. Chaves e Amaral (2016) compreendem que o grande volume de recursos associados ao Fies e ao ProUni destinados às instituições privadas contribui para que o quantitativo de matrículas continue a aumentar mais no setor privado que no público.

Assim, notamos que, nessas categorias, a legitimação das práticas inspiradas no patrimonialismo pode ser observada de forma mais direta quando ocorre o alargamento da utilização dos recursos públicos nos financiamentos estudantis para o setor privado, conforme explicitado nas Estratégias 12.5 e 12.19 da Meta 12. Esses processos permitiram que o Brasil fosse o campeão mundial na presença de conglomerados educacionais não apenas no ensino superior (com instituições com capital na bolsa de valores), mas também em relação aos serviços intrínsecos à área educacional.

Os traços que constituem a política brasileira não estão distantes de uma agenda global para a educação, conduzida por organismos multilaterais, tais quais o FMI, BID e a OCDE. Entretanto, o processo vem sendo refinado por meio de uma camuflagem (filantropia educacional) já denunciada por Ball (2014) como um aspecto global. Dessa forma, há agora uma nova configuração das práticas que privatizam o 
NEGREIROS, H. L.; AUER, F.; SANTOS, W. do; FERREIRA, E. B.

público, porque o privado, também parceiro, é indutor (empreendedor) da política, em consonância com diretrizes transnacionais.

A valorização profissional também se encontra nessas categorias ("Profissional" e "Ensino Superior"), pois está vinculada ao incentivo, além das formações continuadas (categoria "Educação Básica"), com a realização da pós-graduação, em grande parte feita a distância nas redes privadas, como requisito importante na elevação da remuneração dos professores e na sua competitividade nos concursos públicos. Como exemplo, a Estratégia 14.3 visa a "[...] expandir o financiamento estudantil por meio do Fies à pósgraduação stricto sensu" (BRASIL, 2014, p. 20).

A categoria "Pacto Federativo" expressa a preocupação do PNE com as competências de cada ente da federação, além do financiamento da educação como um todo. Nessa categoria também se encontram as bases legais que deram sustentação às metas do PNE e os apontamentos das fontes de recursos para que cada meta pudesse ser cumprida. O PNE compreende que a falta de normas de cooperação suficientemente regulamentadas faz existirem lacunas na articulação federativa, resultando na descontinuidade das políticas.

Desse modo, logo na apresentação do PNE, esse foco é expressado, vinculando o sucesso em se atingir os objetivos das metas à articulação dos entes federativos. De acordo com o documento, "[...] a busca pela equidade e pela qualidade da educação em um país tão desigual como o Brasil é uma tarefa que implica políticas públicas de Estado que incluam uma ampla articulação entre os entes federativos" (BRASIL, 2014, p. 6).

Todavia, a separação das categorias "Pacto Federativo" e "Educação Básica" é um ponto que chama a atenção, de forma que o primeiro é, em alguma medida, garantidor da segunda, mas aparecem de maneira que não se relacionam. A categoria "Pacto Federativo" é a que se apresenta mais isolada nesse processo.

Logo no início do texto do PNE, há o reconhecimento, por parte dos seus elaboradores, da ausência de normas de cooperação entre os entes federativos que visassem a assegurar uma educação de qualidade, pois, para o documento, "[...] as responsabilidades estão definidas, mas ainda não há normas de cooperação suficientemente regulamentadas" (BRASIL, 2014, p. 8).

A desarticulação denunciada se expressa no próprio $P N E$, sendo visível na Figura 2 pela heterogeneidade entre as classes das quais esperávamos um maior imbricamento. Apesar de a Meta 15 estabelecer justamente que, no prazo de um ano, em regime de colaboração dos três entes federativos, seja desenvolvida uma política nacional de formação de professores da educação básica, esse expediente não é detalhado e nem é mencionada a forma como isso se daria. O PNE apenas diz, de maneira genérica, que o Pacto Federativo deve ser fortalecido, sem traçar caminho para isso.

Esses expedientes de aprofundamento das relações público-privado estão em consonância com as recomendações dos organismos multilaterais, especialmente o BM, nas quais as políticas educacionais dos países em desenvolvimento deveriam estar embasadas nos princípios gerencialistas de eficiência e acountability. A solução encontrada está na terceirização da atividade-fim. Essa também é a saída apregoada pelos novos comandantes da política educacional brasileira, as Organizações Não Governamentais (ONGs) e as instituições filantrópicas que participam das políticas educacionais. Evangelista e Leher (2012) entendem que o novo gerencialismo, agora parte da escola, abre caminho para a intervenção de grupos privados nos sistemas

Inter-Ação, Goiânia, v.46, n.1, p. 149-165, jan./mar. 2021. Disponível em: <http://dx.doi.org/10.5216/ia.v45i3.64915>. 
públicos de ensino, considerados como detentores do know-how que salvará a educação pública.

Além da Meta 15, a Meta 19 e a Meta 20 mencionam as responsabilidades da União, contudo seguem a mesma lógica do estabelecido na Meta 15, ou seja, abordam de maneira genérica a participação da União e deixam em aberto os procedimentos a serem tomados para a melhoria da eficiência do Pacto Federativo.

A Meta 20 é a de maior importância em relação ao investimento público em educação, sobretudo no que diz respeito à parte que cabe à União. No ano de 2018, a porcentagem do investimento público em educação, em relação ao Produto Interno Bruto (PIB), foi de 5,83\%. A meta previa $7 \%$ até o final de 2019 , entretanto isso não ocorreu, já que não houve crescimento do investimento público na área educacional nesse ano, portanto já estamos fora da meta estabelecida (BRASIL, 2019).

Nessa direção, quando não há clareza dos caminhos que devem ser traçados para o alcance das metas, não há percurso a ser seguido pelos governantes e, dessa forma, as possibilidades de não se sentirem responsabilizados são maiores. Esse afastamento pode ser percebido na Figura 2, pois a categoria "Pacto Federativo" está isolada das categorias com as quais deveria ter maior entrelaçamento, "Educação Básica", e "Educação Superior". Esse distanciamento é notado pela intenção do atual governo em rever a Meta 20, com o intuito de reduzir o percentual de investimento (AGÊNCIA BRASIL, 2019).

Entendemos que o destaque do setor privado no PNE assegura o afastamento, por parte do Estado, de suas obrigações com o financiamento da educação e sua maior participação no Pacto Federativo. Além disso, compreendemos que as ausências do Estado fazem parte da estratégia de ceder espaço para o setor privado, que não o ocupa em um movimento explícito de tensionamento, mas pela concessão de acordos previamente instituídos.

\section{CONSIDERAÇÕES FINAIS}

Pesquisas no campo da política educacional (DALE, 2015; VERGER, 2019; GOMES; SILVA; OLIVEIRA, 2019; ADRIÃO, 2018) vêm destacando o quadro de disputa no contexto da globalização neoliberal com efeitos graves no campo da educação pública e gratuita, cujas políticas são impulsionadas pelos Estados nacionais e influenciadas por agentes privados nacionais e internacionais com base em um projeto radical de mercantilização da educação.

Desde a década de 1990, sob o domínio da racionalidade neoliberal, e agora ultraliberal, esta disputa entre o público e o privado assume contornos mais complexos, e uma avalanche de reformas são implantadas por meio da legislação e de programas de ação governamental que visam a acompanhar um padrão de aprendizagem e de controle de valores e ideias que devem fazer parte de uma sociedade globalizada, marcada pelos interesses da empresa capitalista.

Esse quadro é desenvolvido no Brasil, cuja cultura patrimonialista ainda está presente nos dias de hoje, o que pode aprofundar a histórica interferência do privado no público. O estudo aqui apresentado observa que o PNE legitima a diluição das fronteiras 
NEGREIROS, H. L.; AUER, F.; SANTOS, W. do; FERREIRA, E. B.

entre o público e o privado no campo da educação. Se, de um lado, a utilização de investimentos públicos na esfera privada colabora para o cumprimento das metas do $\mathrm{PNE}$, de outro lado, a educação brasileira fica esvaziada de seu sentido público devido aos interesses privados que a atingem. Subentendemos que, se a educação é um bem público e social que deve ser garantida pelo Estado, não cabe ser conduzida pelo setor privado.

Artigo recebido em: 10/08/2020

Aprovado para publicação em: 03/11/2020

\section{REMINISCENCES OF PATRIMONIALISM IN THE NATIONAL EDUCATION PLAN (2014-2024)}

ABSTRACT: This article aims to analyze how the goals and strategies of the National Education Plan (2014-2024) show, in the public-private relationship, the transformations and permanences of Brazilian patrimonialism. It is characterized as a documentary research and its source is the National Education Plan (2014-2024). Among the theoretical contribution, it mobilizes the concepts of patrimonialism and public-private relations. It uses the IRAMUTEQ software as an instrument to aid in data production. The results point to the permanence of Brazilian patrimonialism, but with changes in the public-private relationship due to the strengthening of third sector entities.

KEYWORDS: Education. National Education Plan. Patrimonialism. Public-private Relations.

\section{REMINISCENCIAS DEL PATRIMONIALISMO EN EL PLAN NACIONAL DE EDUCACIÓN (2014-2024)}

RESUMEN: Este artículo tiene como objetivo analizar cómo las metas y estrategias del Plan Nacional de Educación (2014-2024) muestran, en la relación público-privada, las transformaciones y permanencias del patrimonialismo brasileño. Se caracteriza por ser una investigación documental y su fuente es el Plan Nacional de Educación (2014-2024). Entre el aporte teórico, moviliza los conceptos de patrimonialismo y relaciones público-privadas. Utiliza el software IRAMUTEQ como instrumento para ayudar en la producción de datos. Los resultados apuntan a la permanencia del patrimonialismo brasileño, pero con cambios en la relación público-privada a través del fortalecimiento de entidades del tercer sector.

PALABRAS CLAVE: Educación. Plan Nacional de Educación. Patrimonialismo. Relaciones públicoprivadas.

NOTA

Inter-Ação, Goiânia, v.46, n.1, p. 149-165, jan./mar. 2021. Disponível em: <http://dx.doi.org/10.5216/ia.v45i3.64915>. 
1- O professor Dermeval Saviani é enfático ao demonstrar, de forma racional e sistemática, que historicamente a educação brasileira foi atravessada e, ainda, é constituída por relações "promíscuas" entre o público e o privado.

\section{REFERÊNCIAS}

ADRIÃO, T. Dimensões e formas da privatização da educação no Brasil: caracterização a partir de mapeamento de produções nacionais e internacionais. Currículo sem Fronteiras, Rio de Janeiro, v. 18, n. 1, p. 8-28, jan./abr. 2018.

AGÊNCIA BRASIL. Reportagem: MEC quer alterar a meta de investimento de $10 \%$ do PIB. Disponível em: https://agenciabrasil.ebc.com.br/educacao/noticia/2019-07/mec-queralterar-meta-de-investimento-de-10-do-pib.2019. Acesso em: 22. mar. 2019.

ARAÚJO, L. Estado da arte da relação público e privado na educação básica. Revista de Financiamento da Educação, Porto Alegre, v. 5, n. 8, p. 1-11, jan./ abr. 2015.

BALL, S. J. Educação Global SA: novas redes políticas e o imaginário neoliberal. Ponta Grossa: UEPG, 2014.

BANCO MUNDIAL. Um ajuste justo: análise da eficiência e equidade do gasto público no Brasil. 2017. Disponível em: https://www.worldbank.org/pt/country/brazil/publication/ brazil-expenditure-review-report. Acesso em: 1 jun. 2019.

BRUNS, B.; LUQUE, J. Professores excelentes - como melhorar a aprendizagem dos estudantes na América e no Caribe. Overview booklet. Washington, D.C.: Banco Mundial, 2014.

BRASIL [Constituição (1988)]. Constituição da República Federativa do Brasil. Brasília: Senado $\quad$ Federal, $1988 . \quad$ Disponível em: http://www.planalto.gov.br/ccivil_03/constituicao/constituição.htm. Acesso em: 14 nov. 2019.

BRASIL. Lei no 11.494, de 20 de junho de 2007. Regulamenta o fundo de manutenção e desenvolvimento da educação básica e de valorização de profissionais da educação, Brasília, 20 jun. 2007. Disponível em: http://www2.camara.leg.br/legin/fed/lei/2007/lei11494-20-junho-2007-555612-normaatualizada-pl.pdf. Acesso em: 17 dez. 2019.

BRASIL. Lei n 13.005, de 25 de junho de 2014. Aprova o Plano Nacional de Educação (PNE) e dá outras providências, Brasília. 2014. Disponível em: http://www.planalto.gov.br/ccivil_03/_ato20112014/2014/lei/l13005.htm\#: :text=LEI\%20N\%C2\%BA\%2013.005\%2C\%20DE\%2025,Art. Acesso em: 1 mar. 2020. 
NEGREIROS, H. L.; AUER, F.; SANTOS, W. do; FERREIRA, E. B.

BRASIL. Lei n 9.394, de 20 de dezembro de 1996. Estabelece as diretrizes e bases da educação nacional. Brasília. 1996. Disponível em: http://portal.mec.gov.br/seed/arquivos/pdf/tvescola/leis/lein9394.pdf. Acesso em: 12 nov. 2019.

BRASIL. Portal da Transparência: Controladora-Geral da União. 2019. Disponível em http://www.portaltransparencia.gov.br/funcoes/12-educacao?ano=2018. Acesso em: 2 maio 2020.

CHAVES, V. L. J.; AMARAL, N. C. Política de expansão da educação superior no Brasil: o ProUni e o Fies como financiadores do setor privado. Educação em Revista, Belo Horizonte, v. 32, n. 4, p. 49-72, dez. 2016.

DALE, R. Conjunctions of power and comparative education. Compare: A Journal of Comparative and International Education, London, v. 45, n. 3, p. 341-362, 2015.

EVANGELISTA, O.; LEHER, R. Todos pela educação e o episódio Costin no MEC: a pedagogia do capital em ação na política educacional brasileira. Trabalho Necessário, Rio de Janeiro, v. 10, n. 15, p. 1-29, jul./dez. 2012.

FAORO, R. Existe um pensamento político no Brasil. São Paulo: Ática 1993.

FAORO, R. Os donos do poder: formação do patronato político brasileiro. Rio de Janeiro: Biblioteca Azul, 2017.

FERNANDES, M. D. E.; BRITO, S. H. A.; PERONI, V. M. V. Sistema e Plano Nacional de Educação: notas sobre conceituação, relação público-privado e financiamento. Estudos RBEP, Brasília, v. 93, n. 235, p. 565-578, set./dez. 2012.

GOMES, S.; SILVA, A.; OLIVEIRA, F. Governos partidários e políticas educacionais no Brasil do século XXI: a eficácia da democracia. In: ARRETCHE, M.; MARQUES, E. (org.). As políticas da política: desigualdades e inclusão nos governos do PSDB e do PT. São Paulo: Editora Unesp, 2019. p. 217-242.

HOLANDA, S. B. História geral da civi1izacão brasileira: a época colonial. 17. ed. Rio de Janeiro: Editora Bertrand do Brasil, 1971. t. I, v. 1.

HOLANDA, S. B. Raízes do Brasil. São Paulo: Companhia das Letras, 1995.

HYPÓLITO, A. M. BNCC, agenda global e formação docente. Retratos da Escola, Brasília, v. 13, n. 25, p. 187-201, jan./maio 2019.

INSTITUTO NACIONAL DE ESTUDOS E PESQUISAS EDUCACIONAIS ANÍSIO TEIXEIRA. Relatório do $2^{\circ}$ ciclo de monitoramento das metas do plano nacional de educação - 2018. Brasília: Inep, 2018. Disponível em: http://pne.mec.gov.br/publicacoes/item/download/15_43f943e1c8b9aaf756af3875d85 61a10. Acesso em: 2 maio. 2020.

Inter-Ação, Goiânia, v.46, n.1, p. 149-165, jan./mar. 2021. Disponível em: <http://dx.doi.org/10.5216/ia.v45i3.64915>. 
MENDONÇA, E. F. Estado patrimonial e gestão democrática do ensino público no Brasil. Educação \& Sociedade, Campinas, v. 22, n. 75, p. 84-108, ago. 2001.

MINTO, L. W. Educação superior no PNE (2014-2024): apontamentos sobre as relações público-privadas. Revista Brasileira de Educação, Rio de Janeiro, v. 23, p. 1-17, jul./set. 2018.

PINTO, J. M. R. Uma análise da destinação dos recursos públicos, direta ou indiretamente, ao setor privado de ensino no Brasil. Educação \& Sociedade, Campinas, v. 37, n. 134, p. 133-152, jan./mar. 2016.

POCHMANN, M.; FERREIRA, E. B. Escolarização de jovens e igualdade no exercício do direito à educação no Brasil: embates do início do século XXI. Educação \& Sociedade, Campinas, v. 37, n. 137, p. 1241-1267, 2016.

TEIXEIRA, G. V. A participação do setor privado na gestão da educação básica pública em municípios mineiros. 2017. 214 f. Dissertação (Mestrado em Educação) Instituto de Ciências da Educação, Universidade Federal do Pará, Belém, 2013.

VERGER, A. A política educacional global: conceitos e marcos teóricos chave. Práxis Educativa, Ponta Grossa, v. 14, n. 1, p. 1-25, jan./abr. 2019.

Heitor Lopes NeGREROS: Graduado em Educação Física (Bacharelado e Licenciatura) pela Universidade Vila Velha; mestrando do Programa de Pós-Graduação em Educação da Universidade Federal do Espírito Santo.

Orcid: https://orcid. org/0000-0001-9394-1907

E-mail: heitornegreiros@hotmail.com

Francella Auer: Graduada em Pedagogia pela Universidade Federal do Espírito Santo; mestranda do Programa de Pós-Graduação em Educação da Universidade Federal do Espírito Santo.

Orcid: https://orcid.org/0000-0002-1913-854X

E-mail: auerfranceila@gmail.com

Wagner doS SANtos: Graduado em Educação Física pela Universidade Federal do Espírito Santo; mestre em Educação pela Universidade Federal de Minas Gerais e doutor em Educação pela Universidade Federal do Espírito Santo. Professor do Programa de PósGraduação em Educação e do Programa de Pós-Graduação em Educação Física da Universidade Federal do Espírito Santo. É pesquisador com bolsa produtividade do Conselho Nacional de Desenvolvimento Científico e Tecnológico (CNPq).

Orcid: https://orcid. org/0000-0002-9216-7291

E-mail:wagnercefd@gmail.com 
NEGREIROS, H. L.; AUER, F.; SANTOS, W. do; FERREIRA, E. B.

Eliza Bartolozzl Ferreira: Graduada em História; mestre em Educação pela Universidade Federal do Espírito Santo; doutora em Educação pela Universidade Federal de Minas Gerais, com pós-doutoramento na École Normale Supérieure de Lyon/França. Professora Associada da Universidade Federal do Espírito Santo e do Programa de PósGraduação em Educação. É pesquisadora com bolsa produtividade do Conselho Nacional de Desenvolvimento Científico e Tecnológico (CNPq).

Orcid: https://orcid.org/0000-0002-4100-9875

E-mail: elizappge@gmail.com

Este periódico utiliza a licença Creative Commons Attribution 3.0, para periódicos de acesso aberto (Open Archives Iniciative - OAI). 